\title{
Effect of Radiotherapy Dose Rates on Early Intestinal Toxicity
}

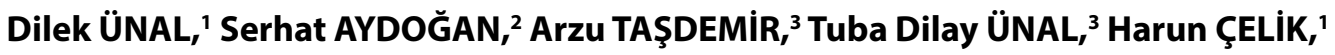 \\ Hatice KARAMAN, ${ }^{3}$ Celalettin EROĞLU, ${ }^{4}$ Bünyamin KAPLAN ${ }^{4}$ \\ 'Department of Radiation Oncology, Kayseri Training and Research Hospital, Kayseri-Turkey \\ ${ }^{2}$ Department of Anesthesiology and Reanimation, Kayseri Training and Research Hospital, Kayseri-Turkey \\ ${ }^{3}$ Department of Pathology, Kayseri Training and Research Hospital, Kayseri-Turkey \\ ${ }^{4}$ Department of Radiation Oncology, Erciyes University Faculty of Medicine, Kayseri-Turkey
}

\begin{abstract}
OBJECTIVE
The aim of the present study was to investigate early histopathological changes in small intestinal tissue caused by radiotherapy (RT) applications with varying dose rates in rats.

\section{METHODS}

Thirty rats were divided into 3 groups. The first and second groups were irradiated at $300 \mathrm{MU} / \mathrm{min}$ and 600 $\mathrm{MU} / \mathrm{min}$, respectively. The third was a control group. On day 7 following RT application, small intestine tissue samples were obtained.

\section{RESULTS}

Mucosal thickness was significantly lower in the $300 \mathrm{MU} / \mathrm{min}$ group, compared to the other groups, and thickness was significantly lower in the $600 \mathrm{MU} / \mathrm{min}$ group, compared to the control group. Villus length was significantly decreased in the $300 \mathrm{MU} / \mathrm{min}$ group, compared to the other groups, and villus width was significantly increased in the control group, compared to the other groups.
\end{abstract}

\section{CONCLUSION}

RT application with high dose may be less toxic for tissue with high risk for acute toxicity, such as that of the small intestine.

Keywords: Radiotherapy dose rate; rat; small intestine; toxicity.

Copyright $\odot$ 2016, Turkish Society for Radiation Oncology

\section{Introduction}

Radiotherapy (RT) is an important cancer treatment option, and is generally used in combination with other treatment alternatives, such as chemotherapy or tumor-removing surgery. Modern technology has allowed for the delivery of localized radiation to nearly every part of the body. However, normal tissue toxic- ity remains the most significant dose-limiting factor in clinical RT applications.[1] Radiation targets cellular DNA and can produce immediate cell death or loss of ability to sustain cell division.[2] In some cell types, cell death occurs rapidly, within several hours of irradiation.[3] This type of death, interphase death, is primarily limited to thymocytes, lymphocytes, spermatogonia, and other cells in rapidly proliferating tissue such 
as that of the small intestine.[4]

Gastrointestinal toxicity can occur after irradiation of thoracic, abdominal, or pelvic malignancies if normal gastrointestinal structures are involved in the RT field. Early gastrointestinal side effects (i.e. acute toxicity) of RT include diarrhea, abdominal pain, nausea, and vomiting, which may develop during or shortly after the completion of a course of RT. In addition, late effects including ulceration, stricture formation, and bowel obstruction may be observed months to years after RT completion. [5] Gastrointestinal toxicity is the most significant dose-limiting side effect in patients receiving RT for pelvic and abdominal tumors. [6,7] These toxicities can limit maximum doses of RT and chemotherapy, and thus may reduce efficacy of treatment.[5]

At the acute (early) period, alterations of the intestinal mucosa, such as protein and fibrin precipitation, inflammation, and edema of the bowel wall, can be histologically detected.[8-10] The number and height of villi decreases, and the affected functioning of the bowel mucosa leads to the loss of proteins, electrolytes, and water. $[8,11,12]$

RT can be administered at different dose rates.[13] Acute and chronic side effects of different RT dose rates are still under investigation. The aim of the present experimental study was to investigate early histopathological changes in small intestinal tissue, which has high risk for acute toxicity of RT, caused by RT applications with different dose rates in rats.

\section{Materials and Methods}

\section{Animals}

Thirty adult female Sprague Dawley rats $(133 \pm 8$ gr $)$ were used. Rats were housed in separate cages and given ad libitum access to food and water. The animals were acclimatized with a 12-hour light/dark cycle. The study was approved by the local Ethics Committee for Animal Studies (No: 15/72).

\section{Study design and animal experimentation}

Rats were divided into 3 groups of 10 each. Rats in the first group were irradiated at $300 \mathrm{MU} / \mathrm{min}$, and those in the second group were irradiated at $600 \mathrm{MU} / \mathrm{min}$ by $6 \mathrm{MV}$ external $\mathrm{x}$-ray beams. Radiation of the total body was $800 \mathrm{cGy}$. The third group was designated as the control group and was not irradiated. Following RT application, the rats were clinically monitored for diarrhea. On day 7 following RT application, all rats were sacrificed under general anesthesia, and small intestine tissue samples were obtained.

Small intestine tissues were fixed in $10 \%$ buffered formalin and embedded in paraffin blocks. Four-micron sections from each paraffin block were cut with a microtome, stained with hematoxylin and eosin, and histopathologically evaluated by light microscopy. $\mathrm{Mu}-$ cosal thickness, and villus length and width were measured, and villus length/crypt rates were calculated for the small intestine of each rat.

\section{Statistical analysis}

SPSS software (version 15.0; SPSS Inc., Chicago, IL, USA) was used for statistical analysis. Continuous variables were presented as mean $\pm \mathrm{SD}$, and statistical analysis of variables was performed with one-way analysis of variance (ANOVA) and Tukey's post hoc test. Qualitative variables were noted in percentages, and the correlation between categorical variables was investigated using chi-square analysis $(\chi 2) ; p<0.05$ was considered significant.

\section{Results}

Histopathological comparison of intestinal findings and severity of diarrhea among the irradiated groups is shown in Table 1. Significant differences were found among the groups regarding mucosal thickness, villus length and width, and presence of diarrhea on day 3 following RT $(\mathrm{p}<0.001, \mathrm{p}=0.002, \mathrm{p}=0.004, \mathrm{p}=0.024$, respectively). Mucosal thickness was significantly decreased in the $300 \mathrm{MU} / \mathrm{min}$ group, compared to the other groups and was significantly decreased in the $600 \mathrm{MU} / \mathrm{min}$ group, compared to the control group (Figure 1). Villus length was significantly decreased in the $300 \mathrm{MU} / \mathrm{min}$ group, compared to the other groups, while there was no significant difference between the $600 \mathrm{MU} / \mathrm{min}$ group and the control group. Villus width was significantly increased in the control group, compared to the other groups, while there was no significant difference between the $300 \mathrm{MU} / \mathrm{min}$ group and the $600 \mathrm{MU} / \mathrm{min}$ group. No significant difference was found among the groups in terms of villus length/crypt rate $(\mathrm{p}>0.05)$.

On day 3 following RT, diarrhea developed in half of the $300 \mathrm{MU} / \mathrm{min}$ and $600 \mathrm{MU} / \mathrm{min}$ groups, while no diarrhea was observed in the control group. Though no significant difference regarding presence of diarrhea on day 7 was found among the groups, the $p$ value bordered statistical significance $(\mathrm{p}=0.082)$. Diarrhea 
Table 1 Histopathological comparison of intestinal findings and severity of diarrhea among experiment groups

\begin{tabular}{lcccc} 
& $\mathbf{3 0 0} \mathbf{~ M U / m i n , ~} \mathbf{n : 1 0}$ & $\mathbf{6 0 0} \mathbf{~ M U / m i n , ~} \mathbf{n : ~ 1 0}$ & Control, n:10 & p value \\
\hline Mucosal thickness $(\mu \mathrm{m})^{\mathrm{a}}$ & $19.7 \pm 3.2$ & $24.4 \pm 4.4$ & $28.6 \pm 3.3$ & $<0.001$ \\
Villus length $(\mu \mathrm{m})^{\mathrm{b}}$ & $12.2 \pm 2.5$ & $14.5 \pm 1.8$ & $15.8 \pm 1.8$ & 0.002 \\
Villus width $(\mu \mathrm{m})^{\mathrm{c}}$ & $4.0 \pm 0.4$ & $4.3 \pm 0.7$ & $5.2 \pm 1.0$ & 0.004 \\
Villus length/crypt rate & $3.2 \pm 1.1$ & $3.0 \pm 0.7$ & $2.9 \pm 0.6$ & 0.791 \\
Development of diarrhea on day 3 (\%) & $5(50.0)$ & $5(50.0)$ & - & 0.024 \\
Presence of diarrhea on day 7 (\%) & $4(40.0)$ & $2(20.0)$ & - & 0.082
\end{tabular}

${ }^{a}$ Mucosal thickness was significantly lower in the $300 \mathrm{MU} / \mathrm{min}$ group, compared to the other groups, and was significantly lower in the $600 \mathrm{MU} / \mathrm{min}$ group, compared to the control group; ${ }^{b}$ Villus length was significantly lower in the $300 \mathrm{MU} / \mathrm{min}$ group, compared to other groups, while no significant difference was found between the $600 \mathrm{MU} / \mathrm{min}$ group and the control group; ' Villus width was significantly higher in the control group, compared to the other groups, while no significant difference was found between the $300 \mathrm{MU} / \mathrm{min}$ group and the $600 \mathrm{MU} / \mathrm{min}$ group.

continued to be observed in $40 \%$ of the $300 \mathrm{MU} / \mathrm{min}$ group and in $20 \%$ of the $600 \mathrm{MU} / \mathrm{min}$ group.

\section{Discussion}

In mammals exposed to radiation in dose ranges of 10 $100 \mathrm{~Gy}$, villi does not regenerate, due to mitotic activity loss in the crypt cells of the small intestine. Villi in the intestinal epithelium gradually disappear, and the inner surface of the intestine is eventually flattened. Time to intestinal damage varies, depending on species. In mice, for example, changes occur after a period of 3 to 4 days, whereas in humans they usually become evident in 10 post-irradiation days. [14,15] Therefore, in order to evaluate effects of various RT dose rates on small intestinal histopathology, rats were sacrificed and tissue samples were obtained on the seventh post-RT day. Results determined that early RT-induced intestinal toxicity was more prominent in animals irradiated with low dose rate (300 MU/min), compared to those irradiated with high dose rate $(600 \mathrm{MU} / \mathrm{min})$. Mucosal thickness, and villus length and width of the small intestine were decreased in animals irradiated with low dose rate, compared to those irradiated with high dose rate.

Gastrointestinal symptoms may begin within hours of radiation exposure but usually develop during the first or second week of RT. Acute injury to the small intestine following irridation is a frequent, dose-dependent event. Low doses produce mild, reversible disease, while higher doses may produce more serious or irreversible injury.[2] Diarrhea, abdominal cramping, nausea, vomiting, and lack of appetite are common early symptoms of radiation enteritis and may result from stimulation of the central nervous centers by substances such as free radicals or endotoxins produced by intestinal bacteria.[2,10] Early radiation-induced vomiting and diarrhea may also be related to increased motility of the small intestine. $[2,16,17]$ Rats were monitored in the present study, and it was observed that diarrhea developed in half the animals in each irradiated group on day 3 following RT. Although no statistically significant difference between the 2 groups was determined, diarrhea was observed with higher frequency in the $300 \mathrm{MU} / \mathrm{min}$ group on day 7 following RT.

Dose rate term refers to the duration of administration of a particular dose. It is a primary factor in determining degree of biological effect generated by a certain dose of $\mathrm{X}$ and gamma radiation. Decrease in dose rate with prolongation of irridation time also generally reduces the degree of resultant biological effect.
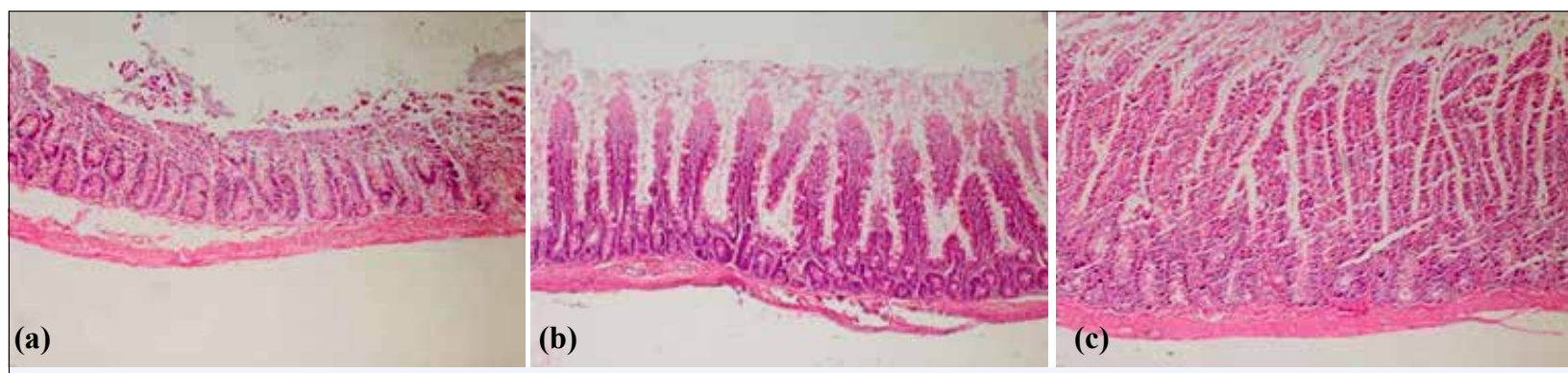

Fig. 1. Effect of radiotherapy dose rate on intestinal mucosal thickness. (a) $300 \mathrm{MU} / \mathrm{min}$ group, (b) $600 \mathrm{MU} / \mathrm{min}$ group, (c) control group [10 x hematoxylin and eosin]. 
Tumor and its microenvironment progress rapidly. Oxygenation of tumor is an important factor in treatment. Hypoxia of tumor affects response to RT, chemotherapy, and even surgery, not only for the treatment of large, bulky tumors, but also for the treatment of very small primary tumors.[18] Hypoxia is an important mechanism of resistance to RT in various tumour types.[19] Anti-cancer agents such as carbogen and nicotinamide, and RT approaches have been investigated for radioresistance of hipoxic tumor cells.[18] Hyperbaric oxygenation and accelerated radiotherapy with carbogen and nicotinamide (ARCON) therapy are examples of these approaches. Increase in effect of RT via simultaneous hyperoxygenation has been targeted in carbogen, nicotinamide, or their combinations, as in ARCON therapy. However, increase in early side effects of RT (i.e. toxicity of normal cells) has been observed in a majority of clinical reporting of carbogen plus nicotinamide or ARCON treatments. [20-25] For example, it has been reported that ARCON therapy for head and neck cancer increased early skin and mucosal reactions.[20-23] It has also been reported that carbogen plus nicotinamide or ARCON therapy of gliomas increased early toxicity of the central nervous system. $[24,25]$ In other words, increased oxygenation during RT increases side effects, as hyperoxygenation of non-malignant cells may increase impression by RT. It is known that hypoxia enhances the radioresistance of non-maling cells such as mesenchymal stromal cells. [26] In applications of intensity-modulated radiotherapy (IMRT), decrease in response to treatment may occur due to overall prolongation of treatment time. However, it has been thought that this condition is compensated by rapid oxygenation. [27] The present results are supported by the afformentioned results. In the present study, the group with longer duration of treatment (i.e. $300 \mathrm{MU} / \mathrm{min}$ ) had more severe intestinal side effects of RT, possibly because longer RT duration increased oxygenation of intestinal tissue. The authors believe that this finding indicates the significance of tissue oxygenation during RT. Vascularization and therefore oxygenation are normal in normal tissues (non-cancerous cells). Therefore, incerased oxygenization with prolongation of RT duration (even with limited minutes) increases RT toxicity in normal tissues such as those of the small intestine.

\section{Conclusion}

Results of the present study suggest that application of RT with high dose rate may be less toxic for tissues with high risk for acute toxicity, such as those of the small intestine.

\section{Acknowledgements}

The authors are grateful for the helpful advice and contribution of A. Celil Unver during the period of research. The present study was supported by the Kayseri Education and Research Hospital Educational Planning Committee [grant no. 13.11.2014/35]. It was presented at the 21st National Cancer Congress in Antalya, Turkey in April 2015.

\section{Disclosure Statement}

The authors declare no conflicts of interest.

\section{References}

1. Wang J, Zheng H, Ou X, Albertson CM, Fink LM, Herbert JM, et al. Hirudin ameliorates intestinal radiation toxicity in the rat: support for thrombin inhibition as strategy to minimize side-effects after radiation therapy and as countermeasure against radiation exposure. J Thromb Haemost 2004;2(11):2027-35.

2. Bismar MM, Sinicrope FA. Radiation enteritis. Curr Gastroenterol Rep 2002;4(5):361-5.

3. Endlich B, Radford IR, Forrester HB, Dewey WC. Computerized video time-lapse microscopy studies of ionizing radiation-induced rapid-interphase and mitosis-related apoptosis in lymphoid cells. Radiat Res 2000;153(1):36-48.

4. Wouters BG. Cell death after irradiation: how, when and why cells die. In: Joiner MC, van der Kogel A, editors. Basic Clinical Radiobiology. 4th ed. London: Hodder Education; 2009. p. 27-40.

5. Czito BG, Meyer JJ, Willett CG. Gastrointestinal toxicity of radiation therapy. http=//www.uptodate. $\mathrm{com} /$ contents/gastrointestinal-toxicity-of-radiation therapy? source=search_result \&search $=$ Gastrointe stinal+toxicity+of+radiation+therapy.\&selectedTit le $=1 \sim 150$ (02 June 2015, date last accessed).

6. Andreyev J. Gastrointestinal complications of pelvic radiotherapy: are they of any importance? Gut 2005;54(8):1051-4.

7. Epidermoid anal cancer: results from the UKCCCR randomised trial of radiotherapy alone versus radiotherapy, 5-fluorouracil, and mitomycin. UKCCCR Anal Cancer Trial Working Party. UK Co-ordinating Committee on Cancer Research. Lancet 1996;348(9034):1049-54.

8. Zimmerer T, Böcker U, Wenz F, Singer MV. Medical 
prevention and treatment of acute and chronic radiation induced enteritis--is there any proven therapy? a short review. Z Gastroenterol 2008;46(5):441-8.

9. Novak JM, Collins JT, Donowitz M, Farman J, Sheahan DG, Spiro HM. Effects of radiation on the human gastrointestinal tract. J Clin Gastroenterol 1979;1(1):939.

10. Summers RW, Flatt AJ, Prihoda MJ, Mitros FA. Effect of irradiation on morphology and motility of canine small intestine. Dig Dis Sci 1987;32(12):1402-10.

11. Hwang JM, Chan DC, Chang TM, Tsao TY, Tsou SS, Lu RH, et al. Effects of oral arginine and glutamine on radiation-induced injury in the rat. J Surg Res 2003;109(2):149-54.

12. Maj JG, Paris F, Haimovitz-Friedman A, Venkatraman E, Kolesnick R, Fuks Z. Microvascular function regulates intestinal crypt response to radiation. Cancer Res 2003;63(15):4338-41.

13. Khamfongkhruea C, Tannanonta C, Thongsawad S. Dosimetric evaluation of radiation dose rate effect in respiratory gated intensity modulated radiation therapy. Biomed Imaging Interv J 2012;8(1):5.

14. Hall EJ, Giaccia AJ. The gastrointestinal syndrome. In: Hall EJ, Giaccia AJ, editors. Radiobiology for the radiologist. 7th ed. Philadelphia: Lippincott Williams \& Wilkins; 2012. p. 116-8.

15. Wiernik G, Plant M. Radiation effects on the human intestinal mucosa. Curr Top Radiat Res 1970:7;32568.

16. Otterson MF, Sarna SK, Moulder JE. Effects of fractionated doses of ionizing radiation on small intestinal motor activity. Gastroenterology 1988;95(5):1249-57.

17. Otterson MF, Sarna SK, Leming SC, Moulder JE, Fink JG. Effects of fractionated doses of radiation on colonic motor activity. Am J Physiol 1992;263(4 Pt 1):518.

18. Rockwell S, Dobrucki IT, Kim EY, Marrison ST, Vu VT. Hypoxia and radiation therapy: past history, ongoing research, and future promise. Curr Mol Med
2009;9(4):442-58.

19. Kaanders JH, Bussink J, van der Kogel AJ. ARCON: a novel biology-based approach in radiotherapy. Lancet Oncol 2002;3(12):728-37.

20. Kaanders JH, Pop LA, Marres HA, van der Maazen RW, van der Kogel AJ, van Daal WA. Radiotherapy with carbogen breathing and nicotinamide in head and neck cancer: feasibility and toxicity. Radiother Oncol 1995;37(3):190-8.

21. Kaanders JH, Pop LA, Marres HA, Liefers J, van den Hoogen FJ, van Daal WA, et al. Accelerated radiotherapy with carbogen and nicotinamide (ARCON) for laryngeal cancer. Radiother Oncol 1998;48(2):115-22.

22. Kaanders JH, Pop LA, Marres HA, Bruaset I, van den Hoogen FJ, Merkx MA, et al. ARCON: experience in 215 patients with advanced head-and-neck cancer. Int J Radiat Oncol Biol Phys 2002;52(3):769-78.

23. Zackrisson B, Franzén L, Henriksson R, Littbrand B, Stratford M, Dennis M, et al. Acute effects of accelerated radiotherapy in combination with carbogen breathing and nicotinamide (ARCON). Acta Oncol 1994;33(4):377-81.

24. Pickles T, Graham P, Syndikus I, Rheaume DE, Duncan GG, Green A, et al. Tolerance of nicotinamide and carbogen with radiation therapy for glioblastoma. Radiother Oncol 1996;40(3):245-7.

25. Miralbell R, Mornex F, Greiner R, Bolla M, Storme G, Hulshof $\mathrm{M}$, et al. Accelerated radiotherapy, carbogen, and nicotinamide in glioblastoma multiforme: report of European Organization for Research and Treatment of Cancer trial 22933. J Clin Oncol 1999;17(10):31439.

26. Sugrue T, Lowndes NF, Ceredig R. Hypoxia enhances the radioresistance of mouse mesenchymal stromal cells. Stem Cells 2014;32(8):2188-200.

27. van der Kogel AJ. The dose-rate effect. In: Joiner MC, van der Kogel A, editors. Basic Clinical Radiobiology. 4th ed. London: Hodder Education; 2009. p. 158-68. 